\title{
Surface Modifications in the Platelets of a Patient with $\alpha-N$-Acetyl-D-Galactosamine Residues, the Tn-Syndrome
}

\author{
Alan T. Nurden, Dominique Dupuis, Dominique Pidard, Nelly Kieffer, \\ Thomas J. Kunicki, and Jean-Pierre Cartron, Unité 150 Institut National \\ de la Santé et de la Recherche Medicale, Hôpital Lariboisière, 75475 Paris \\ Cedex 10; Unité 76 Institut National de la Santé et de la Recherche \\ Medicale, Centre National de Transfusion Sanguine, 75739 Paris Cedex 15, France
}

Abstract The Tn-syndrome is an acquired disorder characterized by the polyagglutination of blood cells and the pathological exposure of $\alpha$-N-acetyl-D-galactosamine residues ( $\mathrm{Tn}$-antigen) at the cell surface. We now report studies on the platelets of a patient $(\mathrm{Ba}$. of which $81 \%$ reacted positively with a fluorescein conjugate of Helix pomatia agglutinin (HPA). The surface proteins of $\mathrm{Ba}$. platelets were labeled with ${ }^{125} \mathrm{I}$ by the lactoperoxidase-catalyzed procedure; single and twodimensional electrophoresis on sodium dodecyl sulfate (SDS)-polyacrylamide gels was followed by autoradiography that revealed normal ${ }^{125}$ I-labeling of the major membrane glycoproteins (GP) but that GP Ib had a faster than normal migration. The abnormal GP $\mathrm{Ib}$ of $\mathrm{Ba}$. platelets was strongly labeled when platelet suspensions were treated sequentially with neuraminidase, galactose oxidase, and sodium $\left[{ }^{3} \mathrm{H}\right]$ borohydride. Unlike the GP Ib of normal human platelets, it was also strongly labeled when $\mathrm{Ba}$. platelets were treated with galactose oxidase and sodium $\left[{ }^{3} \mathrm{H}\right]$ borohydride alone. Both the alloantigen, $\mathrm{Pl}^{\mathrm{Al}}$, and quinidine-dependent antibody receptor activity were normally expressed by $\mathrm{Ba}$. platelets, which also bound a monoclonal antibody (AN51) to GP Ib. Analysis of Ba. platelets by crossed immunoelectrophoresis using a rabbit anti-human platelet antibody preparation revealed the presence of an immunoprecipitate in the GP Ib position that had an abnormal appearance and migration in the second dimension. An altered position of the precipitate given by Factor VIIIR:Ag was also noted. Incorporation of HPA into the agarose gel during the first dimension electrophoresis resulted in the specific precipitation of the abnormal GP Ib of $\mathrm{Ba}$. platelets.

Address reprint requests to Dr. Nurden, Hôpital Lariboisière.

Received for publication 2 April 1982 and in revised form 20 August 1982.
Our studies show that circulating Tn-platelets contain GP Ib with a modified oligosaccharide chain structure responsible for the platelet expression of $\mathrm{Tn}$-antigen activity.

\section{INTRODUCTION}

The Tn-syndrome is a rare pathological state brought about by the exposure of the Tn-antigen on somatic cells. Most early studies described how erythrocytes from Tn-individuals were polyagglutinated by antibodies present in most human sera. Clinically, expression of the Tn-antigen by erythrocytes is of special interest because it is sometimes associated with hemolytic anemia $(1,2)$ and because it has been described in patients with leukemic and preleukemic states (3-5). Several studies have shown that the Tnantigen is expressed following exposure of terminal $\alpha$-glycosidically linked $N$-acetyl-D-galactosamine (GalNAc) ${ }^{1}$ residues at the erythrocyte surface (6-8). Exposure of GalNAc residues can be detected by binding studies with Helix pomatia agglutinin (HPA), which is specific for both the $\alpha$ - and $\beta$-anomer of this sugar (9). Marked alterations in the periodate-Schiff stained patterns were observed following the analysis of membrane glycoproteins (GP) of Tn-erythrocytes by SDS-polyacrylamide gel electrophoresis (SDSPAGE), with the major sialoglycoprotein (glycophorin A) being particularly decreased in staining intensity $(8,10)$. Glycophorin B was also affected (11). A selective loss in $\beta$-3-D-galactosyltransferase ( $\mathrm{T}$-transferase) activity in Tn-erythrocytes suggested that the alkali-

\footnotetext{
${ }^{1}$ Abbreviations used in this paper: CBR, Coomassie Brilliant Blue R250; CIE, crossed immunoelectrophoresis; GalNAc, $N$-acetyl-D-galactosamine; GP, glycoprotein; HPA, Helix pomatia agglutinin; HPA-FITC, HPA-fluorescein isothiocyanate; SDS-PAGE, sodium dodecyl sulfate-polyacrylamide gel electrophoresis; TX-100, Triton X-100.
} 
labile oligosaccharide chains of the glycophorins were being incompletely synthesized $(10,11)$.

Leukocytes and platelets of Tn-individuals have also been shown to be polyagglutinable and a leukopenia and thrombocytopenia is often observed $(2,12-14)$. The frequent association in patients between the exposure of Tn-receptors on erythrocytes and a low platelet count led us to investigate the membrane GP composition of platelets isolated from three Tn-syndrome donors (15). A modified platelet membrane GP composition was detected with membrane GP Ib having a markedly decreased periodate-Schiff staining capacity after SDS-PAGE. Although the abnormality was clearly apparent, it was not determined whether GP Ib was absent or structurally modified. The situation was further complicated by the presence of coexisting subpopulations of normal and Tn-positive platelets that varied in proportion between donors (15). We now describe surface-labeling and other studies performed on the platelets of a patient with $>80 \%$ Tn-positive platelets. Evidence for the presence of GP Ib with structurally abnormal oligosaccharide chains is provided together with data to suggest that the modified GP Ib is responsible for the platelet expression of Tn-antigen activity.

\section{METHODS}

Materials. All materials for SDS-PAGE were of electrophoresis purity grade and were obtained from Bio-Rad Laboratories (Richmond, CA). These included the high and low molecular weight protein standards used for molecular weight determination by SDS-PAGE. Carrier-free $\mathrm{Na}^{25} \mathrm{I}$ $(100 \mathrm{mCi} / \mathrm{ml}$ in $\mathrm{NaOH}$ solution, $\mathrm{pH} 8-11$ ) was obtained from the Radiochemical Center (Amersham, England), ${ }^{51} \mathrm{Cr}$ as sodium chromate in normal saline $\mathrm{pH} \sim 8(200-5,000 \mathrm{Ci} / \mathrm{g}$ chromium, $1 \mathrm{mCi} / \mathrm{ml}$ ) from New England Nuclear (Dreieich, West Germany). Neuraminidase (Vibrio cholera, $1 \mathrm{U} / \mathrm{ml}$ ) was purchased from Behringwerke AG (Marburg/Lahn, West Germany), galactose oxidase $(400 \mathrm{U} / \mathrm{ml})$ from Kabi Diagnostics Ltd. (Stockholm, Sweden), and sodium $\left[{ }^{3} \mathrm{H}\right]$ borohydride $(16 \mathrm{Ci} / \mathrm{mmol})$ from the Commissariat à l'Energie Atomique (Saclay, France). HPA and HPA conjugated with fluorescein (HPA-FITC) were products of Reactifs IBF (Villeneuve-La-Garenne, France). The film used for autoradiography and fluorography was Kodak X-omat MA (Kodak-Pathé, Paris, France). EN $^{3}$ HANCE was obtained from New England Nuclear. The anti-P1 ${ }^{\wedge 1}$ and quinidinedependent antibodies used in this study were kindly donated by Dr. R. Aster (The Blood Center, Milwaukee, WI). The monoclonal hybridoma antibody (AN51) and ${ }^{25}$ I-labeled $(\mathrm{Fab})_{2}$ fragments of a rabbit anti-mouse IgG $(50 \mu \mathrm{Ci} / \mu \mathrm{g}$ protein) were provided by Dr. G. Tobelem (Hôpital Lariboisière) from a stock given by Dr. A. J. McMichael (John Radcliffe Hospital, Oxford, England). The agarose used for crossed immunoelectrophoresis was agarose-type HSA from Litex (Glostrup, Denmark). Rabbit antihuman Factor VIIIR:Ag serum was purchased from Behringwerke, rabbit antiglycocalicin serum was generously donated by $\mathrm{Dr}$. N. $\mathrm{O}$. Solum (Rikshospitalet, Oslo, Norway).

Subjects. The patient with Tn-syndrome (Ba.) is a 32-yrold woman whose erythrocytes have been extensively studied
$(8,10,16)$. Over $90 \%$ of the circulating population of erythrocytes have been shown to be $\mathrm{Tn}$-positive. The patient has been studied by us on four occasions during a period of 3 yr. A low circulating platelet count was consistently observed (Table I). The patient is a blood group $\mathrm{O}$ donor, because of this and our extensive use of HPA lectin during the course of our study only donors with blood group $\mathrm{O}$ activity were selected as controls (see Discussion).

Isolation and washing of platelets. Blood $(9 \mathrm{vol})$ was taken by venepuncture directly into an acid-citrate-dextrose anticoagulant (1 vol) as described previously (17). The blood was centrifuged at $120 \mathrm{~g}$ for $15 \mathrm{~min}$ at $15^{\circ} \mathrm{C}$ to obtain platelet rich plasma. The platelets were washed three times in 10 $\mathrm{mM}$ Tris- $\mathrm{HCl}, 0.15 \mathrm{M} \mathrm{NaCl}, 1 \mathrm{mM}$ EDTA, $\mathrm{pH} 7.4$ according to the procedures of Nurden et al. (18).

Immunofluorescent detection of Tn-antigen on platelets. Washed platelets from $\mathrm{Ba}$. and from a normal donor were resuspended at $10^{6}$ platelets $/ \mathrm{ml}$ in phosphate-buffered saline (PBS) containing $1 \%$ bovine serum albumin, pH 7.4. Samples $(0.2 \mathrm{ml})$ were centrifuged onto microscope slides in a Shandon-Elliot Cytospin centrifuge (Instruments Scientifiques Industriels, Paris, France) at $2,000 \mathrm{rpm}$ for $10 \mathrm{~min}$. The slides were air-dried, fixed with methanol for $10 \mathrm{~min}$ at room temperature, washed, and incubated with HPA-FITC $(10 \mu \mathrm{g} /$ $\mathrm{ml}$ in PBS) for $30 \mathrm{~min}$ at $4^{\circ} \mathrm{C}$. After extensive washing at $4^{\circ} \mathrm{C}$ in cold PBS the smears were mounted in PBS-glycerine and examined using a Zeiss fluorescent microscope (CarlZeiss, Inc., Strasbourg, France) equipped with epi-illumination and the appropriate filter for fluorescein. Photographs were taken with an Ektachrome ASA 200 film push-pulled to ASA 800. Tn-positive platelets were visible owing to their bright fluorescence, $\mathrm{Tn}$-negative platelets were revealed by counter-staining with Evans blue according to standard histochemical procedures (19) and visualized using the same fluorescent microscope equipped with a red filter. In quantitative studies at least 500 platelets were evaluated as being HPA-positive or negative.

Lactoperoxidase-catalyzed iodination. Washed control and $\mathrm{Ba}$. platelets were resuspended at $10^{\circ} / \mathrm{ml}$ in $10 \mathrm{mM}$ Tris$\mathrm{HCl}, 0.15 \mathrm{M} \mathrm{NaCl}, 1 \mathrm{mM}$ EDTA, pH 7.4. Lactoperoxidasecatalyzed ${ }^{125}$-labeling of the platelet surface proteins was then performed using the procedure of Phillips and Poh Agin (20) as described by Nurden et al. (18).

Galactose oxidase labeling procedures. The labeling procedures for incorporating ${ }^{3} \mathrm{H}$ into the surface-exposed carbohydrate chains of platelet membrane glycoproteins were

TABLE I

Laboratory Studies on Tn-Platelets

\begin{tabular}{lccc}
\hline \multicolumn{1}{c}{ Subject } & $\begin{array}{c}\text { Whole blood } \\
\text { platelet count }\end{array}$ & $\begin{array}{c}\text { Platelet } \\
\text { protein }\end{array}$ & $\begin{array}{c}\text { Platelet sialic } \\
\text { acid }\end{array}$ \\
\hline & $10^{3} / \mathrm{cu} / \mathrm{mm}$ & $\mathrm{mg} / 10^{\circ}$ platelets & $\mu \mathrm{gg} / \mathrm{mg}$ protein \\
Ba. (4) & $70-90^{\circ}$ & 3.25 & 4.2 \\
Controls (20) & $160-400^{\circ}$ & $3.85 \pm 1.22 \ddagger$ & $7.0 \pm 0.81$ \\
\hline
\end{tabular}

The numbers in parentheses represent the number of times the patient has been examined and the corresponding number of control donors giving rise to the control range. The values given for the patients platelet protein and sialic acid levels are the mean of the results obtained.

- Range.

† Mean \pm SD. 
adapted from McGregor et al. (21). Washed control and Ba platelets were resuspended at $10^{9} / \mathrm{ml}$ in PBS, pH 7.4. Neuraminidase digestion was performed by incubating the platelets for $15 \mathrm{~min}$ at $37^{\circ} \mathrm{C}$ after the addition of neuraminidase $(1 \mathrm{U} / \mathrm{ml}$ in $0.05 \mathrm{M}$ sodium acetate, $0.15 \mathrm{M} \mathrm{NaCl}, 0.009 \mathrm{M}$ $\left.\mathrm{CaCl}_{2}, \mathrm{pH} 5.5\right)$ to a final concentration of $0.1 \mathrm{U}$ enzyme $/ \mathrm{ml}$. The digestion was performed in volumes of $1 \mathrm{ml}$ and terminated by the addition of $9 \mathrm{ml} 10 \mathrm{mM}$ Tris- $\mathrm{HCl}, 0.15 \mathrm{M}$ $\mathrm{NaCl}, 3 \mathrm{mM}$ EDTA, pH 7.4 (Tris-EDTA). The platelets were sedimented by centrifugation at $2,000 \mathrm{~g}$ for $10 \mathrm{~min}$ and resuspended in $1 \mathrm{ml}$ vol of PBS. These platelets, or suspensions of platelets in PBS that had not been treated with neuraminidase, were incubated with galactose oxidase $(10 \mathrm{U} / \mathrm{ml}$, final concentration) for $5 \mathrm{~min}$ at $37^{\circ} \mathrm{C}$ after which each suspension was again made up to $10 \mathrm{ml}$ with Tris-EDTA. The platelets were sedimented, each pellet resuspended in $1 \mathrm{ml}$ PBS, and sodium $\left[{ }^{3} \mathrm{H}\right]$ borohydride $(0.5 \mathrm{mCi})$ added. The suspensions were left at room temperature for $15 \mathrm{~min}$ before Tris-EDTA was added to $10 \mathrm{ml}$. The labeled platelets were washed twice with $10-\mathrm{ml}$ volumes of Tris-EDTA. Control experiments were also performed in which no enzymes were added and the washed platelet suspensions treated directly with sodium $\left[{ }^{3} \mathrm{H}\right]$ borohydride.

SDS-PAGE procedures. Washed, unlabeled, ${ }^{125} \mathrm{I}$-labeled, or ${ }^{3} \mathrm{H}$-labeled platelets were resuspended at $2 \times 10^{9}$ platelets/ $\mathrm{ml}$ in $10 \mathrm{mM}$ Tris- $\mathrm{HCl}, 0.15 \mathrm{M} \mathrm{NaCl}, 3 \mathrm{mM}$ EDTA, $5 \mathrm{mM}$ $N$-ethylmaleimide, $\mathrm{pH} 7.0$. A 1/5-vol of $12 \%$ (wt/vol) SDS was added and the samples solubilized by heating at $100^{\circ} \mathrm{C}$ for $5 \mathrm{~min}$. When no disulphide reduction was performed the samples are said to be nonreduced. To obtain reduced samples the SDS-solubilized proteins were incubated at $37^{\circ} \mathrm{C}$ for $1 \mathrm{~h}$ with $5 \%$ (vol/vol) 2-mercaptoethanol. Single dimension SDS-PAGE was performed using $7-12 \%$ exponential gradient acrylamide slab gels of dimensions $10 \mathrm{~cm}$ (height) $\times 14 \mathrm{~cm}$ (length) $\times 0.15 \mathrm{~cm}$ (thickness). A $1-\mathrm{cm} 3.0 \%$ acrylamide stacking gel was also used. Electrophoresis was performed using the Laemmli (22) buffer systems as we have described previously (18). Sample volumes contained 100 $\mu \mathrm{g}$ SDS-solubilized protein. The two-dimensional nonreduced/reduced system of SDS-PAGE (20) was used according to the procedures detailed by Nurden et al. (18). Briefly, first dimension electrophoresis was performed using $7 \%$ acrylamide rod gels and nonreduced samples. Disulphide bond reduction was performed after electrophoresis by incubating the unstained gels in $10 \mathrm{mM}$ Tris- $\mathrm{HCl}, 1 \mathrm{mM}$ EDTA and $5 \%$ $\mathrm{vol} / \mathrm{vol} 2$-mercaptoethanol, $\mathrm{pH} 7.0$, for $1 \mathrm{~h}$ at room temperature. Second dimension electrophoresis was performed using $0.3-\mathrm{cm}$ thick 7-12\% gradient acrylamide slab gels with $3 \%$ acrylamide stacking gels as described above, the rod gel being held in position over the stacking gel by a small volume of $1 \%$ agarose dissolved in stacking gel buffer. Proteins were detected by Coomassie Brilliant Blue (CBR) staining and ${ }^{125} \mathrm{I}$-labeled proteins by autoradiography of dried CBR stained gels using Kodak X-omat MA film. ${ }^{3} \mathrm{H}$-Labeled proteins were located by fluorography. CBR-stained slab gels that had been washed in $7 \%$ acetic acid were incubated for $\mathrm{l} \mathrm{h}$ at room temperature with gentle agitation and sufficient $\mathrm{EN}^{3} \mathrm{HANCE}$ to generously cover the gel. The $\mathrm{EN}^{3} \mathrm{HANCE}$ was then replaced with an identical volume of cold water and the gel agitated for $1 \mathrm{~h}$ to precipitate the scintillator incorporated within the gel. The gel was dried onto filter paper and exposed to Kodak X-omat MA film for up to 3 wk at $-70^{\circ} \mathrm{C}$.

Crossed immunoelectrophoresis (CIE). Washed platelets whose surface proteins has been labeled with ${ }^{125}$ I by the lactoperoxidase-catalyzed procedure, were resuspended at $6 \times 10^{9}$ platelets $/ \mathrm{ml}$ in $0.038 \mathrm{M}$ Tris- $\mathrm{HCl}, 0.1 \mathrm{M}$ glycine, $\mathrm{pH}$
8.7 (Tris-glycine). A $1 / 10 \mathrm{vol}$ of $10 \%$ (vol/vol) Triton X-100 (TX-100) prepared in Tris-glycine was added. The suspension was agitated at $4^{\circ} \mathrm{C}$ for $30 \mathrm{~min}$, then centrifuged at $100,000 \mathrm{~g}$ for $1 \mathrm{~h}$ at $4^{\circ} \mathrm{C}$. CIE of the TX-100 soluble protein was performed at $15^{\circ} \mathrm{C}$ according to the procedures of Hagen et al. $(23,24)$ as used by Kunicki et al. (25-27). Briefly, $100 \mu \mathrm{g}$ TX-100 soluble protein was electrophoresed at $10 \mathrm{~V} / \mathrm{cm}$ for $\sim 1 \mathrm{~h}$ in first-dimension gels consisting of $1 \%$ agarose, $0.5 \%$ (vol/vol) TX-100 in Tris-glycine. Electrophoresis in the second dimension was performed at $2 \mathrm{~V} / \mathrm{cm}$ for $18 \mathrm{~h}$ into a biphasic gel system consisting of $(a)$ an intermediate gel containing either $1 \%$ agarose, $0.5 \%$ (vol/vol) TX100 in Tris-glycine, or a mixture of monospecific antiserum and the same solution, and $(b)$ an upper gel containing $1 \%$ agarose, $0.5 \%$ (vol/vol) TX-100 in Tris-glycine and the isolated IgG of a rabbit anti-human platelet serum $(800 \mu \mathrm{g} /$ $\mathrm{cm}^{2}$ ) prepared against washed normal platelets. Details of the immunization procedure and isolation of the IgG by ammonium sulfate precipitation and DEAE-cellulose chromatography have been given elsewhere $(23,25)$. The antibody pool used in the present experiments was the same as that used by Kunicki et al. (27). In certain experiments antihuman Factor VIIIR:Ag serum $(50 \mu \mathrm{l})$ or anti-glycocalicin serum $(300 \mu \mathrm{l})$ was incorporated into the intermediate gel before the second dimension electrophoresis. In other experiments HPA was incorporated into the first dimension gel at final concentrations of 50 and $20 \mu \mathrm{g} / \mathrm{ml}$, respectively.

Antibody binding assays. A well-characterized serum containing quinidine-dependent antibody activity and a second serum containing antibodies reactive with the human platelet alloantigen, $\mathrm{P} 1^{\wedge 1}$, were selected as previously described (28). Quinidine-dependent antibody receptor and $\mathrm{Pl}^{\mathrm{Al}}$ antigen activity in $\mathrm{Ba}$. platelets were assayed by the ability of the platelets to inhibit ${ }^{51} \mathrm{Cr}$-release from normal platelets in the presence of antibody and, for the quinidinedependent antibody, the drug. Techniques for the ${ }^{51} \mathrm{Cr}$-labeling of platelets and the assay of antibody reactive sites by inhibition of ${ }^{51} \mathrm{Cr}$-release were as described by Kunicki et al. (28-30). Briefly, platelets from a member of the hospital staff, previously shown to be homozygous for $\mathrm{P} 1^{\mathrm{Al}}$, were isolated and labeled with ${ }^{51} \mathrm{Cr}$ for the assay. The ${ }^{51} \mathrm{Cr}$-labeled platelets were resuspended at $10^{8} / \mathrm{ml}$ in PBS. Test suspensions of washed $\mathrm{Ba}$. platelets and those of a second control donor were prepared at a concentration of $10^{9} / \mathrm{ml}$ as described (28-30) and a series of eight dilutions (see legend to Fig. 5) used in the assay. Volumes $(20 \mu \mathrm{l})$ of the diluted platelet suspensions were then incubated for $2 \mathrm{~h}$ at $37^{\circ} \mathrm{C}$ in the presence of $20 \mu \mathrm{l}$ of a standard dilution of the chosen antiserum. Quinidine sulfate, $1 \mathrm{mM}$ in PBS, was also added at a final concentration of $10^{-4} \mathrm{M}$ in the assay for drug-dependent antibody activity. Samples $(20 \mu \mathrm{l})$ of ${ }^{51} \mathrm{Cr}$-labeled platelets and freshly prepared plasma $(100 \mu \mathrm{l})$, as a complement source, were then added together with $20 \mu \mathrm{l} 0.1 \mathrm{M}$ $\mathrm{MgCl}_{2}$, and the incubation continued for a further $2 \mathrm{~h}$ at $37^{\circ} \mathrm{C}$. At the end of this period the reaction was stopped, the platelets sedimented and the degree of inhibition of platelet lysis determined as previously described (28-30). AN 51 is a monoclonal hybridoma antibody against GP Ib, it does not fix complement (31) and therefore could not be used in the above assay. Instead, receptor activity was measured by indirect radioactive binding assay as described by McMichael et al. (31). Formaldehyde-fixed suspensions of control and $\mathrm{Ba}$. platelets suspended at $10^{9}$ platelets $/ \mathrm{ml}$ in PBS, were incubated with serial dilutions of AN51 ascitic fluid or nonimmune mouse serum for $1 \mathrm{~h}$ at room temperature. The platelets were twice washed and incubated with ${ }^{125}$ I-labeled $(\mathrm{Fab})_{2}$ fragments of a rabbit anti-mouse IgG an- 
tibody for a further $2 \mathrm{~h}$ at room temperature. The platelets were again washed and their associated gamma-radioactivity counted in a gamma counter.

Sialic acid determination. Total platelet sialic acid was measured by the thiobarbituric acid method of Aminoff (32) following its release by hydrolysis with $0.1 \mathrm{~N} \mathrm{H}_{2} \mathrm{SO}_{4}$ at $80^{\circ} \mathrm{C}$ for $1 \mathrm{~h}$ as previously described by us (18). Results were expressed as micrograms sialic acid/milligram platelet protein, protein being measured by the method of Lowry et al. (33).

\section{RESULTS}

Tn-syndrome platelets. The patient Ba. showed a moderate thrombocytopenia (Table I) with blood counts of 70-90 $\times 10^{3} / \mu$ l being typical findings over the 3-yr period she has been studied. The protein content of the isolated platelets was in the normal range but the level of sialic acid associated with the platelet protein was markedly reduced. Platelet morphology as studied by standard electron microscopic procedures was normal, no evidence to suggest the presence

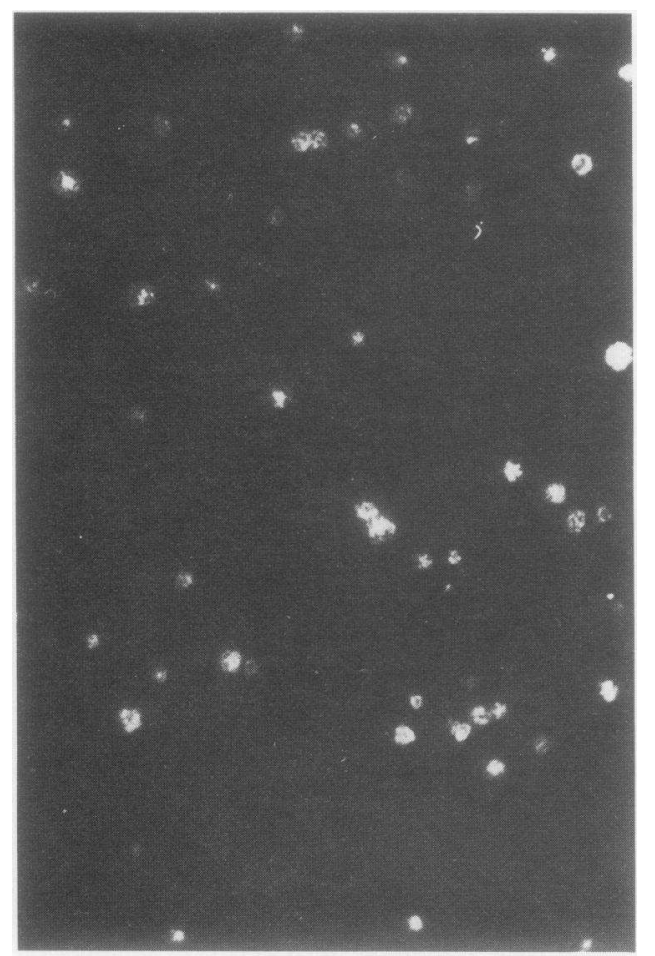

Figure 1 Immunofluorescent detection of Tn-antigen on Ba. platelets using a fluorescein conjugate of HPA lectin Washed platelets were resuspended in PBS containing $1 \%$ bovine serum albumin and aliquots $(0.2 \mathrm{ml})$ centrifuged onto microscope slides as detailed in Methods. Slides were airdried, fixed with methanol, and reacted with $100 \mu \mathrm{l} \mathrm{HPA-}$ FITC $\left(10 \mu \mathrm{g} / \mathrm{ml}\right.$ in PBS) for $30 \mathrm{~min}$ at $4^{\circ} \mathrm{C}$. After extensive washing the smears were mounted in glycerine-PBS and examined under a Zeiss fluorescent microscope equipped with epi-illumination and the appropriate filter for fluorescein. of an increased proportion of large or giant platelets was obtained (data not shown). The presence of terminal $\mathrm{N}$-acetyl galactosamine residues on the platelet surface was investigated by HPA-labeling with the fluorescein conjugate of the lectin (Fig. 1). A large proportion of the platelets of $\mathrm{Ba}$. were strongly labeled with the lectin. Normal human platelets exhibited no fluorescence (not illustrated). Quantitative studies performed using a double-staining procedure (see Methods) revealed that $81 \%$ of the circulating platelets of Ba. were HPA-positive.

Analysis of ${ }^{125}$ I-labeled platelets. The surface proteins of platelets isolated from $\mathrm{Ba}$. have been labeled with ${ }^{125}$ I by the lactoperoxidase-catalyzed procedure and the labeled proteins separated by SDS-PAGE. Nonreduced samples were first analyzed, typical labeling patterns as obtained following autoradiography of the dried gels are shown in Fig. 2. GP nomenclature is that previously used and defined by Nurden et al. (18). Zones of radioactivity corresponding to GP Ia, IIa, IIb, and IIIa were normally detected on analysis of Ba. platelets. However, the band normally located in the GP Ib position appeared to have a faster mobility when $\mathrm{Ba}$. platelet samples were analyzed. The calculated apparent molecular weight of this band was smaller by $\sim 10,000$ daltons than GP Ib of normal

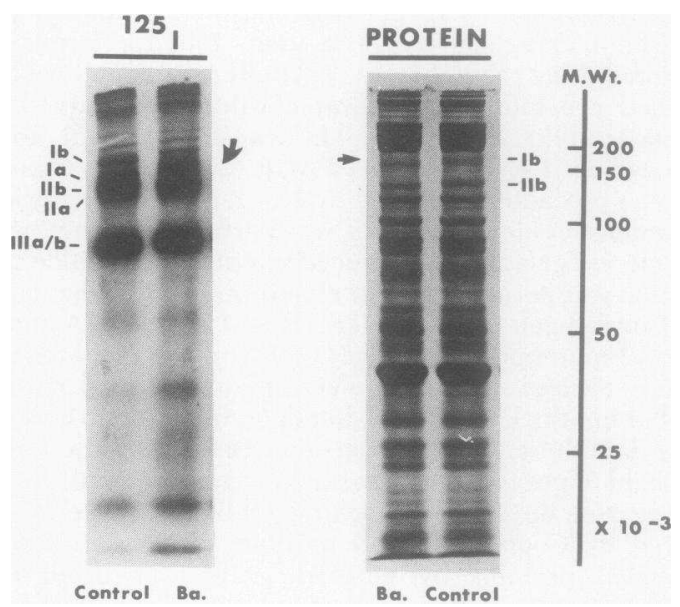

FIgURE 2 Single-dimension electrophoresis of the ${ }^{125} \mathrm{I}$-labeled surface proteins of $\mathrm{Ba}$. and normal human platelets. Washed platelet suspensions were incubated with ${ }^{125} I$ and the surface proteins labeled by the lactoperoxidase-catalyzed iodination procedure as described in Methods. Aliquots of nonreduced SDS-solubilized protein $(100 \mu \mathrm{g})$ were analyzed by SDS-PAGE on 7-12\% exponential gradient acrylamide slab gels. Proteins were detected by CBR-staining. The absence or displacement of a weakly stained band given by GP $\mathrm{Ib}$ on the $\mathrm{Ba}$. platelet pattern is highlighted (small arrow). ${ }^{125} \mathrm{I}$-Labeled proteins were detected on dried gels by autoradiography. Using this procedure $\mathrm{Ib}$ appeared present but of a faster migration (heavy arrow). 
platelets (Table II). Analysis of the protein composition of Ba. platelets by SDS-PAGE followed by CBR-staining revealed a normal polypeptide profile with no evidence of proteolytic degradation of platelet proteins. A faintly stained band (see Fig. 2) constituting the upper of a doublet of CBR-staining polypeptides has been previously identified as that being given by GP Ib (18). This band was absent or displaced on the Ba. platelet profile.

Two-dimensional SDS-PAGE analysis. GP Ib of normal platelets is a high molecular weight GP composed of two subunit chains linked by one or more disulfide bonds $(20,34)$. On disulfide reduction a large $\alpha$-subunit $\left(M_{\mathrm{r}} 143,000\right)$ is separated from a smaller $\beta$-subunit $\left(M_{\mathrm{r}} 22,000\right)(20)$. Single dimension electrophoresis of reduced samples of ${ }^{125} \mathrm{I}$-labeled platelet proteins was performed to see if $\mathrm{Ba}$. platelet GP Ib $\alpha$ also migrated faster than normally during SDS-PAGE. However, the close migration of Ib $\alpha$, IIa, Ic $\alpha$, and IIb $\alpha$ after disulfide reduction, prevented an accurate assessment of any mobility change. The nonreduced/reduced two dimensional system of SDS-PAGE of Phillips and Poh Agin (20) gives an improved separation of individual membrane GP. Fig. 3 compares the analysis of ${ }^{125} \mathrm{I}$-labeled $\mathrm{Ba}$. and normal human platelets by this procedure. It may now be clearly observed that the GP Ib $\alpha$ of $\mathrm{Ba}$. platelets had migrated faster relative to IIa and IIb $\alpha$ during the second dimension of the electrophoresis. Other than this change the patterns are comparable, emphasizing the specificity of the GP Ib abnormality of Ba. platelets. GP $\mathrm{Ib} \beta$ of normal human platelets labels poorly with ${ }^{125}$ I during lactoperoxydase-catalyzed iodination $(20)$ and cannot be observed for either normal or $\mathrm{Ba}$. platelets on Fig. 3 . Analysis of increased amounts of protein $(300 \mu \mathrm{g})$ did allow detection of GP $\mathrm{Ib} \beta$ by CBR staining. It was

TABLE II

GP Molecular Weight Determinations after SDS-PAGE

\begin{tabular}{|c|c|c|c|c|}
\hline \multirow[b]{3}{*}{ Labeling probe } & \multicolumn{4}{|c|}{ GP nomenclature } \\
\hline & \multicolumn{2}{|c|}{ Control } & \multicolumn{2}{|c|}{ Ba. } \\
\hline & Ib & Ilb & $\mathrm{Ib}$ & IIb \\
\hline${ }^{125} I$ & 162,000 & 131,000 & 152,000 & 129,000 \\
\hline$N+{ }^{125} I^{\bullet}$ & 168,000 & 124,000 & NP & NP \\
\hline $\mathrm{GaO}+{ }^{3} \mathrm{H}$ & - & - & 150,000 & - \\
\hline $\mathbf{N}+\mathrm{GaO}+{ }^{3} \mathbf{H}$ & 160,000 & 124,000 & 145,000 & 123,000 \\
\hline
\end{tabular}

Estimations are of nonreduced samples coelectrophoresed on 7$12 \%$ gradient gels with reduced protein standards (see Methods). $\mathrm{N}$, neuraminidase, $\mathrm{GaO}$, galactose oxidase, NP, not performed.

- In this experiment platelets were incubated with neuraminidase, as described in the Methods, prior to the lactoperoxidase-catalyzed ${ }^{125}$ I-labeling of platelet surface proteins.
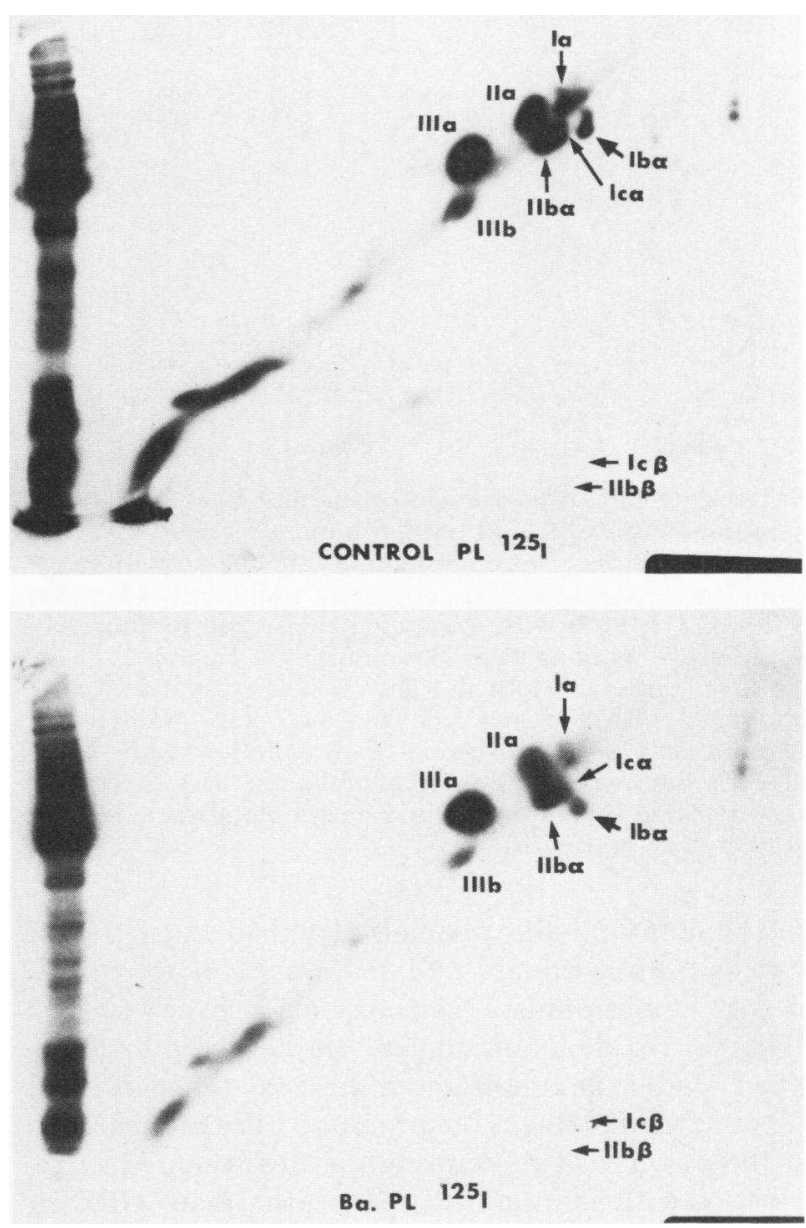

Figure 3 Two-dimensional SDS-PAGE of the ${ }^{125}$ I-labeled surface proteins of $\mathrm{Ba}$. and normal human platelets. Washed ${ }^{125}$ I-labeled platelets were solubilized with SDS in the presence of $N$-ethylmaleimide and samples ( $100 \mu \mathrm{g}$ protein) subjected to first dimension electrophoresis using $7 \%$ acrylamide rod gels. After electrophoresis, the unstained gels were incubated for $1 \mathrm{~h}$ in the presence of $5 \% 2$-mercaptoethanol and second dimension electrophoresis of the now reduced proteins performed on $7-12 \%$ gradient slab gels. A single aliquot of reduced ${ }^{125} \mathrm{I}$-labeled proteins $(100 \mu \mathrm{g})$ of the sample being analyzed was also applied to one side of the slab gel. ${ }^{125}$ I-Labeled proteins were detected on dried gels by autoradiography. A faster migration of GP Ib $\alpha$ in the second dimension on the $\mathrm{Ba}$. platelet pattern can be clearly observed by comparing its position relative to IIb $\alpha$ on both profiles. Note that, as illustrated, the first dimension electrophoresis was from right to left.

located in a position perpendicular to $\mathrm{Ib} \alpha$ on the $\mathrm{Ba}$. profile, it had a normal migration in the second dimension (data not shown).

Labeling with galactose oxidase and sodium $\left[{ }^{3} \mathrm{H}\right]$ borohydride. Fig. 4 shows typical fluorograms as obtained following the analysis by SDS-PAGE of nor- 

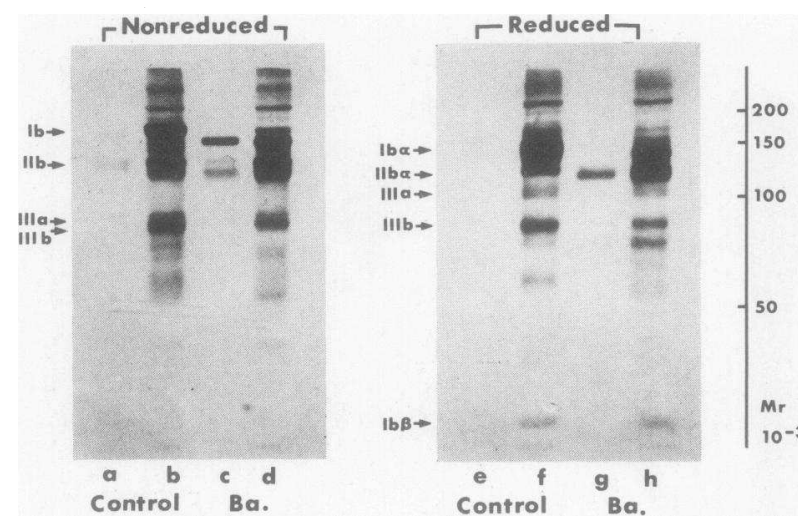

Figure 4 Single-dimension electrophoresis of ${ }^{3} \mathrm{H}$-labeled membrane GP of $\mathrm{Ba}$. and normal human platelets. Washed platelet suspensions were sequentially incubated with neuraminidase, galactose oxidase and sodium $\left[{ }^{3} \mathrm{H}\right]$ borohydride $(b, d, f, h)$ or with galactose oxidase and sodium $\left[{ }^{3} \mathrm{H}\right]-$ borohydride without prior neuraminidase treatment (a, c, e, g) as detailed in Methods. The ${ }^{3} \mathrm{H}$-labeled platelets were solubilized with SDS and analyzed on $7-12 \%$ gradient acrylamide gels in the absence of $(a-d)$ or following $(e-h) d i-$ sulfide reduction with 2 -mercaptoethanol. ${ }^{3} \mathrm{H}$-Labeled GP were detected by fluorography. Control platelets $(a, b, e, f)$, Ba. platelets (c, d, g, h)

mal human and Ba. platelets that had been treated with galactose oxidase and sodium $\left[{ }^{3} \mathrm{H}\right]$ borohydride; or with neuraminidase, galactose oxidase, and sodium $\left[{ }^{3} \mathrm{H}\right]$ borohydride. Nonreduced samples were first analyzed. Under the conditions of the assay the membrane GP of normal platelets incorporated little radioactivity in the absence of neuraminidase digestion. After incubation with neuraminidase, however, many GP were labeled, with GP Ib the dominant GP on the fluorogram. When platelets from $\mathrm{Ba}$. were incubated with neuraminidase before the labeling procedure, a major part of the radioactivity normally to be located in the Ib position was of a faster migration, being closer to GP IIb on the fluorogram. A small band also remained in the equivalent position of Ib of normal platelets. In marked contrast with the results obtained for normal platelets, the faster migrating band in the GP Ib region on the $\mathrm{Ba}$. pattern was also strongly labeled when the platelets were treated with galactose oxidase and sodium $\left[{ }^{3} \mathrm{H}\right]$ borohydride alone. The absence of a requirement for neuraminidase treatment for labeling to be observed in the abnormal GP Ib of Ba. platelets suggested the presence of terminal galactose or $N$-acetyl galactosamine residues. Measurement of the apparent molecular weight of this band (Table II) showed a 10,000- to 15,000-dalton decrease compared with GP Ib of normal platelets.

Reduced samples of Ba. platelets were also analyzed. The modified GP Ib $\alpha$ was heavily labeled and migrated in a similar position to, or perhaps even slightly faster than, GP IIb $\alpha$ (Fig. 4). GP Ib $\beta$ also labels positively with ${ }^{3} \mathrm{H}$ when washed normal human platelets are incubated with neuraminidase, galactose oxidase, and sodium $\left[{ }^{3} \mathrm{H}\right]$ borohydride. The position of GP $\mathrm{Ib} \beta$ is shown on Fig. 4. This band was identified by its diminution on the fluorograph after analysis of ${ }^{3} \mathrm{H}$ labeled Bernard-Soulier platelets where both $\alpha$ - and $\beta$-subunits of GP Ib are lacking $(35,36)$. GP $\operatorname{Ib} \beta$ was of a normal migration on the pattern given by ${ }^{3} \mathrm{H}$ labeled $\mathrm{Ba}$. platelet glycoproteins. It did not label positively when platelets were incubated with galactose oxidase and sodium $\left[{ }^{3} \mathrm{H}\right]$ borohydride alone.

Interaction of $\mathrm{Ba}$. platelets with monospecific antibodies to platelet surface components. The membrane receptor for quinidine-dependent antibodies is absent from Bernard-Soulier platelets (29) and is thought to be associated with membrane GP Ib (30). The quinidine-dependent antibody receptor activity of $\mathrm{Ba}$. platelets was studied by assessing the ability of washed platelet suspensions to inhibit the complementdependent lysis of ${ }^{51} \mathrm{Cr}$-labeled normal human platelets in the presence of the drug and antibody. Fig. 5A shows that $\mathrm{Ba}$. platelets expressed quinidine receptor activity and that quantitatively the receptor activity was close to the normal range. The $\mathrm{P} 1^{\mathrm{Al}}$ platelet alloantigen is carried by membrane GP IIIa (37). Using an identical assay to that for estimating drug-dependent receptor activity, $\mathrm{Pl}^{\mathrm{Al}}$ antigen expression in $\mathrm{Ba}$. platelets was the same as that of platelets isolated from a donor homozygous for the $\mathrm{P}^{\mathrm{Al}}$ antigen (data not shown). The monoclonal platelet antibody, AN51, is directed against human platelet membrane GP Ib (31). Fig. 5B shows that Ba. platelets clearly bound this antibody, quantitatively the binding was slightly below the normal range.

Analysis of $\mathrm{Ba}$. platelets by crossed immunoelectrophoresis. Previous studies on the analysis of human platelet membrane GP by CIE, using a multispecific rabbit antibody preparation raised against normal platelets, have led to the identification of immunoprecipitates given by GP Ia, IIa, the IIb/IIIa complex, IIIb, and Ib (Kunicki et al. 26, 27). Washed suspensions of $\mathrm{Ba}$. platelets whose surface proteins had been labeled with ${ }^{125}$ I by the lactoperoxidase-catalyzed procedure, were incubated with TX-100 and the solubilized proteins analyzed by CIE. Results are shown in Fig. 6, CBR-stained plates are illustrated. Two major differences were apparent on comparing the pattern obtained for Ba. platelets with that of control platelets analyzed under identical conditions. The normal precipitate given by GP Ib was missing from the Ba. platelet pattern, being replaced by a new, more intensely staining immunoprecipitate that had migrated less far in the second dimension. To ascertain whether this new precipitate was related to GP Ib, CIE was per- 

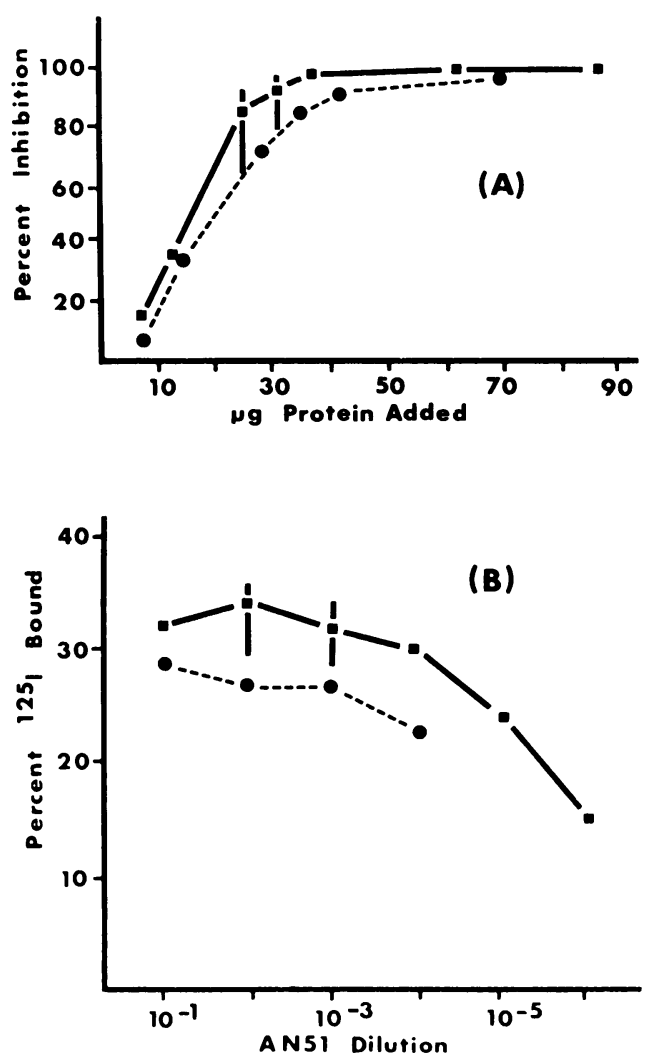

Figure 5 Interaction of $\mathrm{Ba}$. and normal human platelets with monospecific antibodies to platelet surface antigens. (A) Ability of $\mathrm{Ba}$. platelets to inhibit the lytic activity of quinidine-dependent anti-platelet antibody. Diluted suspensions $(20 \mu \mathrm{l})$ of $\mathrm{Ba}$. ( - - $)$ and normal human platelets ( - in PBS were incubated with $20 \mu 11 \mathrm{mM}$ quinidine in PBS and $20 \mu \mathrm{l}$ of a fixed dilution (1:24) of a quinidinedependent antibody-containing serum, for $2 \mathrm{~h}$ at $37^{\circ} \mathrm{C}$. The different platelet dilutions tested are given in terms of their final protein concentration on the abscissa. Complement and ${ }^{51} \mathrm{Cr}$-labeled normal human platelets were then added (see Methods) and the incubation continued for a further $2 \mathrm{~h}$ at $37^{\circ} \mathrm{C}$. Results are expressed as the percent inhibition of maximum immune lysis of the ${ }^{51} \mathrm{Cr}$-labeled platelets by the antibody. (B) Ability of Ba. platelets to bind the monoclonal hybridoma antibody, AN51. Volumes $(50 \mu \mathrm{l})$ of formaldehyde-fixed, normal human ( - - a ) and Ba. platelets (- - - suspended at $10^{9}$ platelets per milliliter in PBS were incubated for $1 \mathrm{~h}$ with AN5l ascitic fluid at the dilutions shown on the abscissa. After washing in PBS containing $0.5 \%$ bovine serum albumin, ${ }^{125} \mathrm{I}$-labeled $(\mathrm{Fab})_{2}$ fragments $(\sim 10,000 \mathrm{cpm})$ of a rabbit anti-mouse IgG antibody were added and incubation continued for $2 \mathrm{~h}$. Platelets were twice washed and associated ${ }^{125} \mathrm{I}$ counted in a gamma counter. Results are expressed as the percentage of the total added radioactivity bound to the platelets. Substitution of the AN51 ascitic fluid with nonimmune mouse serum resulted in $<5 \%$ of the total added radioactivity being associated with the platelets. The control platelet curves in $A$ and $B$ are those performed in parallel with the Ba. platelet samples, the vertical bars represent the range of values obtained for platelets of four different control donors studied on other occasions under identical conditions. formed with antiglycocalicin serum in the intermediate gel during the second dimension electrophoresis. The antigen giving rise to this immunoprecipitate was specifically precipitated by the antiglycocalicin serum (Fig. 6C). A tall, faint precipitate present in the $\mathrm{Ib}$ position (Fig. 6B) was not retarded by the antiglycocalicin serum and probably represents an arc that is usually masked on the normal platelet pattern by the Ib precipitate. In addition to those immunoprecipitates containing the GP antigens mentioned above, we have recently identified the precipitates containing fibrinogen, Factor VIIIR:Ag, cold insoluble globulin, albumin, platelet factor 4 and Factor XIII (subunit A) (38). The precipitate given by factor VIIIR:Ag is identified on Fig. 6A. Fig. 6B shows that this immunoprecipitate was either absent or displaced on the Ba. platelet pro-
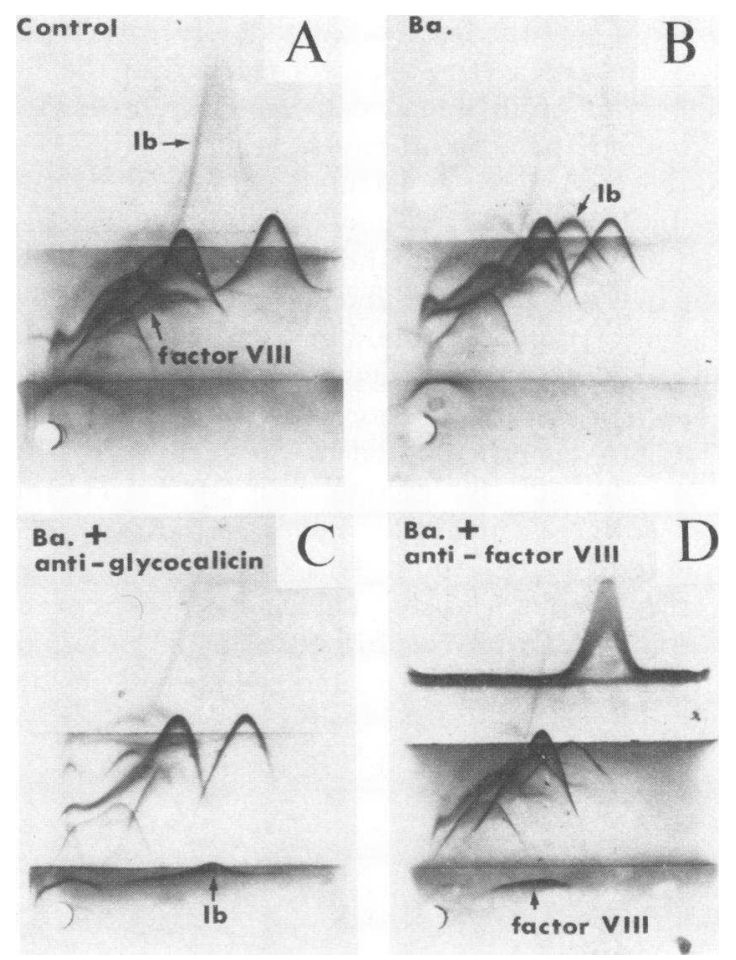

Figure 6 Analysis of normal human and Ba. platelet proteins by CIE. TX-100 soluble platelet proteins $(100 \mu \mathrm{g})$ were separated by a first-dimension electrophoresis in an agarose gel containing the nonionic detergent. Second dimension electrophoresis was performed with the separated antigens migrating across an intermediate gel into an upper gel containing $800 \mu \mathrm{g} / \mathrm{cm}^{2}$ of the immunoglobulin fraction of a rabbit anti-human platelet serum. The intermediate gel either contained no antibody (A, B), antiglycocalicin serum (C) or antifactor VIIIR:Ag serum (D) as detailed in the Methods. The antiglycocalicin serum had been adsorbed with a preparation of soluble platelet proteins lacking (SP Ib as described by Solum et al. (43). The first dimension electrophoresis was from left to right. 
file. In a similar way to that described above for the antiglycocalicin serum, a monospecific antiserum directed against Factor VIIIR:Ag was incorporated into the intermediate gel during the second dimension electrophoresis. A single immunoprecipitate was precipitated by this antiserum from the Ba. platelet samples (Fig. 6D). Thus, the immunoprecipitate given by Factor VIIIR:Ag was not absent but displaced on the Ba. platelet pattern. A close examination of Fig. 6B suggests it had migrated further during the second dimension electrophoresis. The strange appearance, and intense staining of the albumin precipitate in Fig. 6D is thought to be due to the cross-reaction of albumin in the antiserum incorporated in the intermediate gel with antialbumin antibodies in the upper gel. This phenomenon was not observed with the antiglycocalicin serum.

Identification of the GP receptor for HPA lectin. Fig. 1 shows that the bulk of Ba. platelets reacted positively with HPA lectin, a known marker for the Tnantigen on $O$ group blood cells (see Discussion). In order to identify the membrane GP carrying the HPAlectin receptor, the precedents established in other studies by Hagen et al. (23) and by Shulman and Karpatkin (39) were followed, and the lectin incorporated into the first dimension gel during CIE. Fig. 7A shows that the migration of normal human platelet antigens, and in particular GP Ib, was unchanged by the presence of the lectin. In contrast, the modified GP Ib of Ba. platelets was precipitated by the lectin (Fig. 7B). This was a specific interaction with GP Ib, no other platelet antigens, including Factor VIIIR:Ag, were precipitated by the lectin. This conclusion was also supported when ${ }^{125} \mathrm{I}$-labeled $\mathrm{Ba}$. platelets were examined. Autoradiography confirmed both the precipitation of GP Ib by HPA-lectin, and the normal position
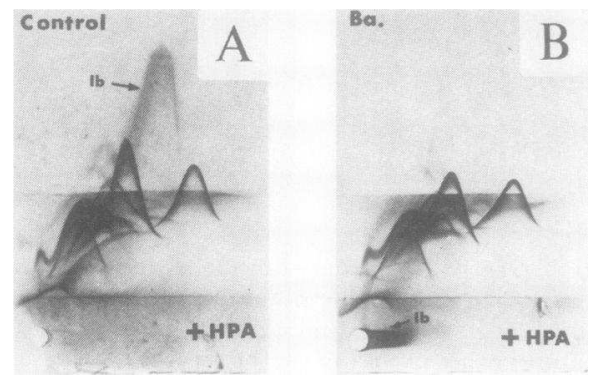

FIGURE 7 Identification of the glycoprotein receptor for HPA in Ba. platelets. CIE of TX-100 soluble extracts of normal human (A) and $\mathrm{Ba}$. platelets (B) was performed as described in the legend to Fig. 6. HPA $(50 \mu \mathrm{g})$ was incorporated into the first-dimension gel. Immunoprecipitation patterns in the absence of added lectin were identical to those shown in Fig. $6 \mathrm{~A}$ and $\mathrm{B}$. The specific precipitation of the abnormal GP Ib of Ba. platelets is illustrated. The first dimension electrophoresis was from left to right. after the second dimension electrophoresis of the immunoprecipitates given by the other major platelet membrane GP antigens. When control platelets were treated with neuraminidase prior to their analysis by CIE with HPA in the first dimension gel, GP Ib was not precipitated by the lectin (data not shown).

\section{DISCUSSION}

Well-defined membrane GP deficiencies are characteristic for the platelets of patients with the congenital platelet disorders, Glanzmann's thrombasthenia and the Bernard-Soulier syndrome (for a review see Nurden and Caen, 40). In the latter disorder, a major platelet lesion is the absence of membrane GP Ib. The platelets of the patient $\mathrm{Ba}$. differ from those of patients with the Bernard-Soulier syndrome in that GP Ib appears to be present although structurally modified. Lactoperoxidase-catalyzed ${ }^{125}$ I-labeling of platelet surface proteins results in the incorporation of ${ }^{125} \mathrm{I}$-into tyrosine or histidine residues of the membrane GP (41). Membrane glycoproteins with an altered oligosaccharide chain composition would be expected to normally incorporate ${ }^{125} \mathrm{I}$ provided that their structural modifications had not resulted in a reorganization of the molecule in the membrane, thus altering the accessibility of the tyrosine residues to the lactoperoxidase. When $\mathrm{Ba}$. platelets were incubated with ${ }^{125} \mathrm{I}, \mathrm{H}_{2} \mathrm{O}_{2}$, and lactoperoxidase, GP Ib was normally labeled but migrated faster on subsequent SDS-PAGE analysis. Ba. platelets were deficient in sialic acid, thus a potential explanation of our finding was that GP Ib was smaller due to a sialic acid deficiency. However, previous studies have shown that when normal human platelets are treated with neuraminidase prior to ${ }^{125}$ I-labeling, the resultant desialated GP Ib migrates more slowly during SDS-PAGE $(18,21)$. This apparent anomaly is probably explained by the fact that the anionic charge of sialic acid actually contributes to the migration of GP Ib during SDS-PAGE. The observed faster than normal migration of GP Ib of $\mathrm{Ba}$. platelets therefore suggests a more severe structural alteration of the molecule than a simple sialic acid deficiency.

Unlike that of normal platelets, GP Ib of Ba. platelets labeled strongly when the platelets were incubated with galactose oxidase and sodium $\left[{ }^{3} \mathrm{H}\right]$ borohydride. Neuraminidase treatment was not a prerequisite for labeling, as it was for the other major membrane GP of $\mathrm{Ba}$. platelets and for all of the membrane GP of normal platelets. This result shows that the abnormal GP Ib of Ba. platelets contains a high proportion of galactose or $\mathrm{N}$-acetylgalactosamine residues in a terminal position on the oligosaccharide chains. Furthermore, analysis of reduced samples following both ${ }^{125}$ Iand ${ }^{3} \mathrm{H}$-labeling procedures suggested that the abnor- 
mality was confined to the larger, $\alpha$-subunit of the molecule. It should be emphasized that the Tn-syndrome is the first reported example of a GP defect that is common to both erythrocytes and platelets. Direct analysis of GP extracted from Tn-erythrocytes have shown that the erythrocytes have a low content of sialic acid and galactose $(7,8)$. The conclusion from these and other studies is that the chief structural determinant of $\mathrm{Tn}$-specificity in erythrocytes is a glycopeptide containing GalNAc residues $\alpha$-glycosidically linked to serine and threonine of glycophorin A (for a review see Anstee, 42). The GalNAc residues are normally substituted to form the disaccharide $\beta$-D-galactosyl (1-3)- $N$-GalNAc, the immunodominant group of the Thomsen-Friedenreich antigen ( $\mathrm{T}$-antigen). The $\mathrm{T}$-antigen itself is substituted with sialic acid and is present as a sialylated tetrasaccharide attached to the MN-sialoglycoprotein.

Although it is too early to make precise predictions concerning the nature of the oligosaccharide chain composition of platelet GP Ib $\alpha$, certain observations can be made. When platelets are homogenized in $\mathrm{Ca}^{2+}$ containing media an endogenous platelet $\mathrm{Ca}^{2+}$-dependent protease degrades GP Ib with the release of a high molecular weight glycopeptide, glycocalicin (43). Glycocalicin has been purified and characterized (44). The principal sugars were found to be galactose, $\mathrm{N}$ acetylglucosamine, GalNAc and sialic acid in a ratio $(2: 1: 1: 2)$ with serine and threonine among the most abundant amino acids. The recent studies of Clemetson et al. (34) have shown that there were great similarities between the tryptic peptide maps of asialoglycocalicin and asialo-GP Ib $\alpha$. It appears that the site of action of the $\mathrm{Ca}^{2+}$-dependent protease that cleaves glycocalicin from GP Ib, is not too distant from the disulfides the cleavage of which separates Ib $\alpha$ and $\mathrm{Ib} \beta$. In all probability, therefore, the oligosaccharide chain composition of GP Ib $\alpha$ resembles that of glycocalicin. The presence of the $\mathrm{T}$-antigen exposed on platelet membranes after neuraminidase digestion has been shown (45). The lectin, peanut agglutinin (Arachis hypogaea) has anti-T specificity (46), binding to terminal galactose residues in glycoproteins. Studies on the binding of ${ }^{125} \mathrm{I}$-labeled lectins to platelet membrane glycoproteins separated by SDS-PAGE have indicated that peanut agglutinin binds specifically to GP Ib $\alpha$ when neuraminidase-treated platelets are being analyzed $(34,47)$. These observations collectively suggest a partial similarity between the oligosaccharide chain composition of platelet GP Ib and the MN-sialoglycoprotein of erythrocytes.

When $\mathrm{Ba}$. platelet proteins were analyzed by CIE it was shown that a prominent glycoprotein antigen, that gave rise to an abnormal precipitate located close to the GP Ib position, was specifically precipitated by antiglycocalicin serum. The glycoprotein was also precipitated by HPA and appeared to be the receptor responsible for the strong fluorescence exhibited by the bulk of $\mathrm{Ba}$. platelets on incubation with the FITC-conjugate of the lectin. As discussed earlier, the Tn-specificity is given by terminal GalNAc residues bound to serine or threonine in an alkali-labile O-glycosidic linkage. This antigen specifically binds Salvia sclarea lectin (46), however, purified Salvia sclarea lectin was not available to us in the present study and HPA lectin was used. HPA is specific for both the $\alpha$ - and $\beta$-anomers of GalNAc (9). It is also known that HPA recognizes GalNAc residues associated with blood group A specificity in addition to Tn determinants $(2,9)$. However, HPA lectin can be safely used in the present studies since our selected patient belongs to the $O$ blood group. As an additional precaution only blood group $\mathrm{O}$ donors were selected as controls. CIE therefore provided additional evidence that $\mathrm{Ba}$. platelets contained GP Ib with GalNAc residues in a terminal position on at least some of its oligosaccharide chains.

Platelets of patients with the Bernard-Soulier syndrome lack the receptor for drug-dependent antibodies that is present on the normal platelet surface and which is thought to be given by membrane GP Ib (29, 30). Ba. platelets normally expressed quinidine-dependent receptor activity thus providing evidence that the antigen is not given by the terminal sugar sequences of the oligosaccharide chains of GP Ib. This finding is in agreement with a previous observation that purified glycocalicin produced no inhibition of quinine-or quinidine-dependent antibody activity (30). Bernard-Soulier platelets also lack the receptor for the monoclonal hybridoma antibody, AN51, which has been shown to be directed against GP Ib by immunoprecipitation reactions (31). Ba. platelets bound AN51 at levels just below the range for platelets of four control donors. This observation provides strong evidence for the normal presence of at least part of the GP Ib molecule on the Ba. platelet surface. McMichael et al. (31) previously showed that the antibody binding to normal platelets was unaffected by neuraminidase treatment. In the Bernard-Soulier syndrome the lack of GP Ib and a low platelet surface sialic acid density is accompanied by the presence of abnormally large platelets in the circulation (see Nurden and Caen, 40). No such morphological abnormalities were observed on examination of $\mathrm{Ba}$. platelets using standard electron microscopy procedures.

An intriguing finding was the observation of two abnormalities when $\mathrm{Ba}$. platelets were analzyed by CIE. In addition to the abnormal precipitate given by the modified GP Ib, the precipitate given by Factor VIIIR:Ag was also in a different position, having apparently migrated much further into the second di- 
mension. This suggested either a modified structure of the Factor VIIIR:Ag of $\mathrm{Ba}$. platelets or that the antigen was present in increased concentrations. Further studies will be required to distinguish between these two possibilities. The fact that considerable evidence points to GP Ib being the receptor for Factor VIIIR:Ag at the platelet surface $(17,34,48,49)$ suggests that a double abnormality affecting GP Ib and Factor VIIIR:Ag in Ba. platelets is not coincidental.

In conclusion, we have presented evidence to show that the majority of the circulating platelets of the patient Ba. contain membrane GP Ib with an abnormal oligosaccharide chain structure associated with the presence of terminal GalNAc residues and the expression of the Tn-antigen. This patient is unique among those we have studied in that a large proportion of the circulating platelets are affected. In other patients, coexisting subpopulations of normal and Tn-platelets varied in proportion from donor to donor (15). The studies that we have reported agree well with the finding of Cartron and Nurden (15) that Tn-platelets have a severely reduced $\mathrm{T}$-transferase activity, the enzyme that adds galactose residues to the C-3 position of $\alpha$ linked GalNAc residues. Thus, GPIb is incompletely synthesized with GalNAc residues remaining in a terminal position. Recent studies have shown that $\mathrm{Tn}$ determinants are also present at the surface of granulocytes as well as platelets and erythrocytes of Tndonors (50), and that the determinants were present in marrow cells with a clonal expression being observed in colonies formed from blood cell precursors. A somatic mutation affecting the $\mathrm{T}$-transferase enzyme in a pluripotent stem cell may well be the origin of the defect. Studies are continuing to characterize the platelet GP Ib defect in the Tn-syndrome, the possible relationship between the abnormality and the low circulating platelet count, and the effect of the defect on platelet function.

\section{ACKNOWLEDGMENTS}

We would like to thank Dr. Douglas Lee (The National Blood Transfusion Service, Lancaster, England) for allowing us to study the patient $\mathrm{Ba}$. We should also like to thank Martine Ohana for secretarial assistance.

Financial support for this study was provided by the Fritz Thyssen Foundation (West Germany).

\section{REFERENCES}

1. Dausset, J., J. Moullec, and J. Bernard. 1959. Acquired hemolytic anemia with polyagglutinability of red blood cells due to a new factor in human serum. Blood. 14: 1079-1093.

2. Bird, G. W. G., N. K. Shinton, and J. Wingham. 1971 Persistent mixed-field polyagglutination. Br. J. Haematol. 21 : 443-453.
3. Bird, G. W. G., J. Wingham, M. J. Pippard, J. G. Hoult, and V. Melikian. 1976. Erythrocyte membrane modification in malignant diseases of myeloid and lymphoreticular tissue. I. Tn-polyagglutination in acute myelocytic leukaemia. Br. J. Haematol. 33: 289-294.

4. Ness, P. M., G. Garraty, P. A. Morel, and H. A. Perkins 1979. Tn-polyagglutination preceding acute leukemia. Blood. 54: 30-34

5. Baldwin, M. L., C. Barrasso, and R. L. Ridolfi. 1979. Tnpolyagglutinability associated with acute myelomonocytic leukemia. Am. J. Clin. Pathol. 72: 1024-1027.

6. Dahr, W., G. Uhlenbruck, and G. W. G. Bird. 1974. Cryptic A-like receptor sites in human erythrocyte glycoproteins: Proposed nature of Tn antigen. Vox Sang. 27: $29-41$.

7. Dahr, W., G. Uhlenbruck, H. H. Gunson, and M. van der Hart. 1975. Studies on glycoproteins and glycopeptides from Tn-polyagglutinable erythrocytes. Vox Sang. 28: 249-252.

8. Dahr, W., G. Uhlenbruck, H. H. Gunson, and M. van der Hart. 1975. Molecular basis of Tn-polyagglutinability. Vox Sang. 29: 36-50.

9. Hammarstrom, S., L. A. Murphy, I. J. Goldstein, and M. E. Etzler. 1977. Carbohydrate binding specificity of four N-acetyl-D-galactosamine- "Specific" lectins: Helix pomatia $A$ hemagglutinin, soy bean agglutinin, lima bean lectin, and Dolichos biflorus lectin. Biochemistry. 16: $2750-2755$.

10. Cartron, J. P., G. Andreu, J. Cartron, G. W. G. Bird, C. Salmon, and A. Gerbal. 1978. Demonstration of T-transferase deficiency in Tn-polyagglutinable blood samples. Eur. J. Biochem. 92: 111-119.

11. Cartron, J. P., D. Blanchard, A. T. Nurden, J. Cartron, C. Rahuel, D. Lee, W. Vainchenker, U. Testa, and H. Rochant. 1982. Tn syndrome: a disorder affecting red blood cell, platelet and granulocyte cell surface components. In Blood Groups and Other Red Cell Surface Markers in Health and Disease. Ch. Salmon, editor. Masson Publishing, USA, Inc., New York. pp. 39-54.

12. Berman, H. J., J. Smarto, C. H. Issitt, P. D. Issitt, W. L. Marsh, and L. Jensen. 1972. Tn activation with acquired A-like antigen. Transfusion (Phila.). 12: 35-45.

13. Sturgeon, P., S. J. Luner, and D. T. McQuiston. 1973. Permanent mixed-field polyagglutinability (PMFP). Serological observations. Vox Sang. 25: 481-497.

14. Beck, M. K., B. L. Hicklin, S. R. Pierce, and R. L. Edwards. 1977. Observations on leucocytes and platelets in six cases of Tn-polyagglutination. Med. Lab. Sci. 34: 325-329.

15. Cartron, J. P., and A. T. Nurden. 1979. Galactosyltransferase and membrane glycoprotein abnormality in human platelets from Tn-syndrome donors. Nature (Lond.). 282: 621-623.

16. Gunson, H. H., J. J. Betts, and J. T. Nicholson. 1971 The electrophoretic mobility of $\mathrm{Tn}$ polyagglutinable erythrocytes. Vox Sang. 21: 455-461.

17. Caen, J. P., A. T. Nurden, C. Jeanneau, H. Michel, G. Tobelem, S. Levy-Toledano, Y. Sultan, F. Valensi, and J. Bernard. 1976. Bernard-Soulier syndrome: A new platelet glycoprotein abnormality. Its relationship with platelet adhesion to subendothelium and with the factor VIII von Willebrand protein. J. Lab. Clin. Med. 87: 586596.

18. Nurden, A. T., D. Dupuis, T. J. Kunicki, and J. P. Caen. 1981. Analysis of the glycoprotein and protein composition of Bernard-Soulier platelets by single and two-di- 
mensional sodium dodecyl sulfate-polyacrylamide gel electrophoresis. J. Clin. Invest. 67: 1431-1440.

19. Pearse, A. G. E. 1961. Histochemistry, theoretical and applied. Churchill Livingstone, Inc., London.

20. Phillips, D. R., and P. Poh Agin. 1977. Platelet plasma membrane glycoproteins. Evidence for the presence of nonequivalent disulfide bonds using nonreduced-reduced two-dimensional gel electrophoresis. J. Biol. Chem. 252: 2121-2126.

21. McGregor, J., K. J. Clemetson, E. James, and M. Dechavanne. 1979. A comparison of techniques used to study externally oriented proteins and glycoproteins of human blood platelets. Thromb. Res. 16: 437-452.

22. Laemmli, U. K. 1970. Cleavage of structural proteins during the assembly of the head of bacteriophage T4. Nature (Lond.). 227: 680-685.

23. Hagen, I., O. J. Bjerrum, and N. O. Solum. 1979. Characterisation of Triton X-100 solubilised human platelet proteins by crossed immunoelectrophoresis. Reference patterns of extracts from whole platelets and isolated membranes. Eur. J. Biochem. 99: 9-22.

24. Hagen, I., A. T. Nurden, O. J. Bjerrum, N. O. Solum, and J. P. Caen. 1980. Immunochemical evidence for protein abnormalities in platelets from patients with Glanzmann's thrombasthenia and Bernard-Soulier syndrome. J. Clin. Invest. 65: 722-731.

25. Kunicki, T. J., D. Pidard, J-P. Cazenave, A. T. Nurden, and J. P. Caen. 1981. Inheritance of the human platelet alloantigen, $\mathrm{P} 1^{\mathrm{A}}$, in type I Glanzmann's thrombasthenia. J. Clin. Invest. 67: 717-724.

26. Kunicki, T. J., D. Pidard, J-P. Rosa, and A. T. Nurden. 1981. The formation of $\mathrm{Ca}^{++}$-dependent complexes of platelet membrane glycoproteins IIb and IIIa in solution as determined by crossed immunoelectrophoresis. Blood. 53: 268-278.

27. Kunicki, T. J., A. T. Nurden, D. Pidard, N. R. Russell, and J. P. Caen. 1982. Characterization of human platelet glycoprotein antigens giving rise to individual immunoprecipitates in crossed immunoelectrophoresis. Blood. 58: 1190-1197.

28. Kunicki, T. J., and R. H. Aster. 1978. Deletion of the platelet-specific alloantigen $\mathrm{Pl}^{\mathrm{A}}$ from platelets in Glanzmann's thrombasthenia. J. Clin. Invest. 61: 1225-1231.

29. Kunicki, T. J., M. M. Johnson, and R. H. Aster. 1978. Absence of the platelet receptor for drug dependent antibodies in the Bernard-Soulier syndrome. J. Clin. Invest. 62: 716-719.

30. Kunicki, T. J., N. Russell, A. T. Nurden, R. H. Aster, and J. P. Caen. 1981. Further studies of the human platelet receptor for quinine- and quinidine-dependent antibodies. J. Immunol. 126: 398-402.

31. McMichael, A. J., N. A. Rust, J. R. Pilch, R. Sochynsky, J. Morton, D. Y. Mason, C. Ruan, G. Tobelem, and J. Caen. 1981. Monoclonal antibody to human platelet glycoprotein I. I. Immunological studies. Br. J. Haematol. 49: 501-509.

32. Aminoff, D. 1961. Methods for the quantitative estimation of $\mathrm{N}$-acetyl neuraminic acid and their application to hydrolysates of sialomucoids. Biochem. J. 81: 384-390.

33. Lowry, O. H., N. J. Rosebrough, A. L. Farr, and R. J. Randall. 1951. Protein measurement with the Folin phenol reagent. J. Biol. Chem. 193: 265-275.

34. Clemetson, K. J., H. Y. Naim, and E. F. Luscher. 1981.
Relationship between glycocalicin and glycoprotein Ib of human platelets. Proc. Natl. Acad. Sci.78: 2712-2716.

35. Nurden, A. T., and D. Dupuis. 1981. The reduced aggregation response of Bernard-Soulier platelets to thrombin may be related to an abnormal glycoprotein $\mathrm{V}$. Thromb. Haemostasis. 46: 22 (Abstr.).

36. Clemetson, K. J., McGregor, E. James, M. Dechavanne, and E. F. Luscher. 1981. Membrane glycoprotein defects in Bernard-Soulier syndrome platelets. Thromb. Haemostas. 46: 108 (Abstr.).

37. Kunicki, T. J., and R. H. Aster. 1979. Isolation and immunologic characterization of the human platelet alloantigen. $\mathrm{Pl}^{\mathrm{Al}}$. Mol. Immunol. 16: 353-360.

38. Nurden, A. T., T. J. Kunicki, D. Dupuis, C. Soria, and J. P. Caen. 1982. Specific protein and glycoprotein deficiencies in platelets isolated from two patients with the gray platelet syndrome. Blood. 59: 709-718.

39. Shulman, S., and S. Karpatkin. 1980. Diminished major antigen in Glanzmann's thrombasthenia and BernardSoulier syndrome. J. Biol. Chem. 255: 4320-4327.

40. Nurden, A. T., D. Dupuis, D. Pidard, T. Kunicki, and J. P. Caen. 1981. Biochemistry and immunology of platelet membranes with reference to glycoprotein composition. Ann. N. Y. Acad. Sci. 370: 72-86.

41. Phillips, D. R. 1980. Surface labeling as a tool to determine structure-function relationships of platelet plasma membrane glycoproteins. Thromb. Haemostasis. 42: 1638-1651

42. Anstee, D. J. 1981. The blood group MNSs-active sialoglycoproteins. Semin. Hematol. 18: 13-31.

43. Solum, N. O., I. Hagen, C. Filion-Myklebust, and T. Stabaek. 1980. Platelet glycocalicin. Its membrane association and solubilization in aqueous media. Biochim. Biophys. Acta. 597: 235-246.

44. Okumura, T., C. Lombart, and G. A. Jamieson. Platelet glycocalicin. II. Purification and characterization. $J$. Biol. Chem. 251: 5950-5955.

45. Glockner, W. M., H. D. Kaulen, and G. Uhlenbruck. Immunochemical detection of the Thomsen-Friedenreich antigen ( $T$-antigen) on platelet plasma membranes. Thromb. Haemostasis. 39: 186-192.

46. Bird, G. W. G. 1977. Erythrocyte polyagglutination. In T. J. Greenwalt and E. A. Steane, editors. Handbook Series in Clinical Laboratory Science, Section D: Blood Banking. CRC Publishing, Cleveland. 1: 443-454.

47. Judson, P., and D. Anstee. 1979. Characterization of membrane glycoproteins of human platelets. In Protides of the Biological Fluids, 27th Colloquium. H. Peeters, editor. Pergamon Press, Oxford, England. pp. 871-874.

48. Cooper, H. A., W. P. Bennett, A. Kreger, D. Lyerly, and R. H. Wagner. 1981. The effect of extracellular proteases from gram-negative bacteria on the interaction of Von Willebrand factor with human platelets. J. Lab. Clin. Med. 97: 379-389.

49. Ruan, C., G. Tobelem, A. J. McMichael, L. Drouet, Y. Legrand, L. Degos, N. Kieffer, H. Lee, and J. P. Caen. 1981. Monoclonal antibody to human platelet glycoprotein I. II. Effects on human platelet function. Br. J. Haematol. 49: 511-519.

50. Vainchenker, W., U. Testa, J-F. Deschamps, A. Henri, M. Titeux, J. Breton-Gorius, H. Rochant, D. Lee, and J-P. Cartron. 1982. Clonal expression of the Tn antigen in erythroid and granulocyte colonies and its application to determination of the clonality of the human megakaryocyte colony assay. J. Clin. Invest. 69: 1081-1091. 